\title{
Same duties, different motives: Ethical theory and the phenomenon of moral motive pluralism
}

\begin{abstract}
While men may all recognize the necessity of keeping contracts, for example, they will offer different reasons for the rule. A Christian will say that God requires it, a Hobbist that the public requires it, a heathen philosopher that virtue requires it. (Locke 1690, I.3.5)

Moral obligation... men of rank call it honor... the vulgar call it honesty, probity, virtue, conscience. Philosophers have given it the names of the moral sense, the moral faculty, rectitude. (Reid, cited in Haakonssen 1996, p. 195)
\end{abstract}

Depending on one's social or cultural perspective, killing them may appear wanton, unchivalrous, dishonorable, brutal, or murderous. (Walzer 2000, p. 43)

- Viewed in its entirety, moral philosophizing, and the moral behavior of people throughout history, presents a curious puzzle. On the one hand, interpersonal duties display a remarkably stable core content: Breakey orality the world over enjoins people to keep their word; refrain from violence, theft and cheating; and help those in need. On the other hand, the asserted motives that drive people's moral actions evince a dazzling diversity: from empathy or sympathy, to practical or prudential reason, to custom and honor, cultural identity, excellence and independence, faith and spirituality, narrative and beauty, and so on and on in an amazing medley. I term this twin phenomenon - a core of fixed moral duties driven by diverse motives_-"moral motive pluralism."

In this article, I marshal evidence to show the phenomenon's prevalence. Contrary to widespread assumptions, across generations and cultures diverse motives drive people to perform their moral duties. But despite this diversity, each different motive impels conscientious compliance with the same core moral duties. Once the prevalence of this phenomenon has been established, I show the phenomenon challenges several key philosophical arguments used to justify popular moral theories, and offers reason to accept certain sorts of ethical theories - especially "functionalist" accounts of morality.

My argument proceeds thus: The first section describes in detail the phenomenon of moral motive pluralism. The second section musters empirical evidence for its prevalence, and considers how far we need to qualify the notion for it to map onto what we know about the extent of cross-cultural moral disagreement. I argue that, while we must qualify the notion sufficiently to allow for the moral disagreement we find between peoples and cultures, even in a qualified form moral motive pluralism remains an intriguing phenomenon. The third section argues for the phenomenon's philosophical significance by showing that its existence undercuts the significance of introspective evidence drawn upon by many historical and contemporary moral 
theories. More positively, if we think that (all else equal) it is a desirable feature of moral theories that they explain pervasive features of morality as it exists in the world, then I argue the existence of moral motive pluralism presses us towards functionalist theories of morality.

A simple observation guides all that follows. Different cultures and philosophies display striking agreement on the sorts of interpersonal behavior they laud as moral. But the motives that each culture and philosophy perceives as driving that behavior are wonderfully diverse.

\section{Moral motive pluralism defined}

This section describes the phenomenon of moral motive pluralism. The phenomenon combines two conditions: "core content convergence" (agreement on morality's core content) and "motive plurality" (diversity in the motives driving moral compliance).

\subsection{Core content convergence}

Morality possesses a shared core content. Here I express it in terms of four core "principles," all invoking a larger theme of reciprocity. ${ }^{1}$ First comes a principle of non-harm and noninterference with others' bodies and properties: one should not murder, assault, rape or steal. Next comes honesty: one should tell the truth, and keep to one's promises and contracts. Cooperativeness fills out the third principle: one should not cheat, and must avoid at least some types of parasitic free-riding. The final principle calls for constrained beneficence: one should help others in need, especially within one's local group and in contexts allowing reciprocity. However, in emergency situations, beneficence extends even to strangers. I will call these four moral principles the "core principles".

This agreement on core principles does not mean that all people acknowledge exactly the same duties. For one thing, these core principles can be contextualized to specific circumstances. Furthermore, core content convergence mandates only a shared core to morality; some moralities may demand further duties regarding sexual propriety, for example, or governing the proper treatment of animals.

Core content convergence applies to interpersonal moralities, and they will be my central focus here. However, it is plausible to think such convergence also applies to political philosophies. For political systems, the overlapping shared moral core mandates democracy, respect for basic human rights, and the over-arching requirement that political authority exists for the common good and the wellbeing of the governed community. After all, there is a clear link between the four core principles - especially the prohibitions on harm and the requirement to help others in need - and the types of entitlements enshrined in the Universal

\footnotetext{
${ }^{1}$ I use "principles" rather than "duties" to avoid a legalistic understanding of the core moral content. Agents must live up to the spirit of the rules as well as their letter. However, I avoid the stronger term "virtues" to resist invoking a thicker, Aristotelian ethic (which I will suggest stands as just one possible moral spring — a 'proximate motive' as I will call itamong others).
} 
Declaration of Human Rights. Just as specific theories of interpersonal morality can add further obligations to the core principles, so too different political theories can add additional entitlements and cultural goals to this minimum 'floor' of basic respect for human wellbeing.

It's worth earmarking one specific version of core content convergence. Let's stipulate "corecontent-convergence $\mathrm{P}$ " (where the "P" stands for "philosophical") to mean that the moral theories put forward by philosophers agree on the four core principles. That is, if we scour the philosophy sections of libraries, we will find myriad moral theories endorsing the core principles. In contrast, "core content convergence" (without hyphenation and the superscript "P") says that the morality actually observed by ordinary people contains this shared content: parents teach the core principles to their children, and demand compliance from their neighbours.

\subsection{Motive plurality}

Motive plurality describes a situation where different individuals and communities possess different motives impelling their performance of (what they perceive as being) their moral duties. We must distinguish motive plurality from the platitude that people can have different motivations for performing discrete acts in specific cases - acts that just-so-happen to align with their moral duties. For example, a shopkeeper wanting to ensure a customer's continued custom might be moved by naked self-interest to behave honestly, and may later be seized by a magnanimous whim to donate to charity. Rather than explaining such sporadic occurrences, motive plurality speaks of distinct and long-lasting motivational structures that, for the person who possesses them, reliably impel the full suite of moral duties recognized by that person. I will call such motivational structures, "proximate motives". Proximate motives are thus defined functionally, in terms of whatever gets the job done, for any given person, to motivate that person's conscientious performance of their perceived moral duties. Each proximate motive will always include one or more values, in the sense defined by Milton Rokeach, as an enduring, singular prescriptive belief about the personal or social desirability of an act or goal. ${ }^{2}$ However, as well as values, proximate motives can contain a wide array of other psychological attributes, including beliefs, attitudes, ideologies, cognitive capacities, perceptual intuitions, personality traits and emotional tendencies. ${ }^{3}$ Examples of proximate motives include empathy, honour, excellence, psychological integrity, universal love, custom, spirituality and enlightened self-interest.

\footnotetext{
${ }^{2}$ Serving as imperatives for action as well as standards for judging actions, Rokeachean values are always "centrally connected" to the subject's cognitive system, interlocking with many other beliefs and attitudes. See Rokeach (1976, pp. 123-124, 159-160).

${ }^{3}$ Rokeach (1976, pp. 111, 123-125, 131) explains many of these disparate psychological attributes. Haidt (2012) provides a similarly inclusive account of the diverse psychological mechanisms underlying conscientious moral behavior. The fact that proximate motives cover such a psychological congeries highlights the breadth of motive plurality: proximate motives differ in kind as well as in content. See $\$ 3.2$ below for a functional account of why this may be so.
} 
Proximate motives possess three key features. Let us use as an example Amy, who we will stipulate possesses a proximate motive of empathy. First, Amy can apprehend her proximate motive introspectively. Empathy plays a role in her subjective experience of the felt "pull" of morality. It also features in Amy's introspected experience of moral deliberation, and in her awareness of the internal rewards and punishments triggered by her acting morally or immorally.

Second, Amy's proximate motive plays a role in all her moral behavior. Empathy does not merely support the performance of one particular duty. Rather, empathy represents the mainstay of Amy's moral life, demanding she conform to all four core principles - even when she feels otherwise disinclined.

Third, Amy views her proximate motive as a fitting ground for moral action. She does not see empathy as just a helpful emotional adjunct. Instead, Amy thinks that empathy contributes to the core principles' normative status. A proper justification of the core principles, as far as Amy is concerned, must somehow connect to the value (or the value-conferring nature) of empathy.

As a result of these three features, when Amy acts conscientiously on the basis of her proximate motive, she fulfils Aristotle's three basic conditions on performing a just action: the action must be done knowingly, must be chosen for its own sake, and must be chosen on the basis of a stable (rather than fleeting) condition (350BC/2002, 1105a).

Observe one clarification and one complication. In terms of the clarification: while the third feature says Amy sees her proximate motive as implicated in some deeper justificatory story, this does not commit her to holding a specific (or, indeed, any) philosophical or theological theory. The fact that empathy impels Amy's moral behavior does not mean Amy believes in Christian agape or in a Humean moral psychology. She may be ignorant of any such notions. While the proximate motive will figure in Amy's deeper theoretical standpoint if she has one, she can still hold her proximate motive without adopting any deeper theory.

Now the complication: sometimes the psychological states that serve as one person's proximate motive can also count as duties for another person. This situation occurs because some moral systems command that their adherents adopt specific psychological states. Consider Bob, who has universal love as his proximate motive. Bob's abiding love for others motivates his every moral action-including observing the core principles. Cathy also feels universal love for others, and similarly observes the core principles. However, Cathy's proximate motive is ultimately a religious one. As a devout Christian, Cathy strives to obey the commandment to 'Love your neighbour as yourself'. The psychological profile that serves as a proximate motive in Bob thus constitutes a duty for Cathy.

This possibility smears any bright-line distinction between proximate motives and resulting duties (and we will see it in action when we survey $\$ 2.2$ 's long lists of proximate motives). However, this complication does not dent the coherence of moral motive pluralism itself. Bob and Cathy each possess a proximate motive (different in each case) and they are both impelled by their proximate motives to perform their moral duties (including observing the 
four principles). Bob and Cathy therefore exhibit core content convergence and motive plurality, and that is all that moral motive pluralism requires. ${ }^{4}$

Just as we noted a theoretical form of core content convergence, so too we can distinguish motive-plurality ${ }^{\mathrm{P}}$ (asserting that different moral philosophies propose different proximate motives) from motive plurality itself (asserting that real people actually possess different proximate motives).

Pooling the results of these last two subsections, moral-motive-pluralism ${ }^{\mathrm{P}}$ means that philosophical theories of morality agree on the core principles, but propose different proximate motives. Moral motive pluralism (without hyphenation or superscript "P") means that actual people and societies agree on the core content of moral duties, but perform those duties on the basis of different motives.

\section{Does moral motive pluralism exist?}

In this section I aim to show that motive plurality is pervasive: human beings hold myriad different proximate motives fuelling their moral behavior. However, I am more circumspect in my claims about core content convergence, allowing that various qualifications may constrain the scope of moral agreement across generations and cultures. Still, even with the appropriate qualifications inserted, I hope to show that a philosophically interesting - and potentially important-level of moral motive pluralism remains. ${ }^{5}$

\subsection{Evidence for core content convergence}

How far do we need to qualify the pure notion of core content convergence in order for it to map onto what we know of ethical theory and moral practice? The extent of core content convergence links into the longstanding philosophical and sociological debate on the extent of 'moral disagreement' reigning in the world (Brink 1984; Gert 2004).

In grappling with this question, it is worth bearing in mind the tendency to focus on difference and disagreement. It is natural to feel surprised (and even alarmed) at another person's or culture's striking differences in, say, norms about sexual propriety, while hardly noticing the countless ways in which the other's morality parallels one's own. As Bernard Gert (2004, p. 125) puts it:

It is not generally recognized that disagreement on the correct answer to a controversial question is compatible with complete agreement that 99 percent of the possible answers are incorrect. It is also compatible with complete agreement on the answers to 99 percent of the moral questions.

\footnotetext{
${ }^{4}$ Far from being a problem for the hypothesis, the complication actually showcases the diversity of people's internal moral psychologies, despite sweeping overlap in their resulting moral duties.

${ }^{5}$ In fact, even without any core content convergence, the phenomenon of motive plurality can still impact on our moral philosophizing. See n. 14 below.
} 
Even so, three qualifications on the scope of claims of convergence seem worth entertaining.

I have already smuggled in the first qualification by speaking of core content convergence. My claim is only that diverse moral systems contain a shared core of principles. It is consistent with this assertion that moral systems may also put forward further duties, and that these may well clash with each other. This qualification thus countenances disagreements on vexing questions like suicide, euthanasia and abortion.

Two further qualifications, in the form of scope restrictions, present themselves. First, we must take seriously the historical fact that prevailing mores routinely endorsed the mistreatment of foreigners, slaves, infidels and women. We might thus hypothesize that core content convergence only applies with respect to the treatment of a person's peers or "in group" - and not with respect to those falling outside his ethnicity, gender, class or tribe.

Second (either as an alternative or additional qualification), we might only recognize core content convergence over a particular locale and period of history. For example, we might acknowledge core content convergence across Western societies since the Enlightenment, but doubt a more universal convergence.

In fact, I suspect that these broad-brush qualifications exclude both too much and too little. They exclude too much in the sense that myriad non-Western and pre-Enlightenment societies observed the core principles, with many long-standing moral codes containing no general exceptions allowing the ill treatment of non-members (as we will soon see). But the two qualifications exclude too little insofar as some modern Western societies failed to observe the four principles, even with respect to in-group morality. (Nazi Germany presents a plausible example, with its aggressive and hyper-competitive intra-group mores.)

Even allowing for such exceptions, I submit that we are still confronted with a phenomenon of convergence worthy of serious attention. If for the last several centuries the overwhelming majority of Western cultures across the globe - and a significant proportion of non-Western cultures before and since-share a fundamental core of moral obligations regulating the treatment of peers, and yet the motives for performing those identical acts differ sharply across individuals and communities, then that fact cries out for philosophical explanation.

But what evidence is there for this degree of core content convergence?

Let's first consider core-content-convergence ${ }^{\mathrm{P}}$, which states that philosophical theories of morality demand the performance of the core principles. With strikingly few exceptions, from Socrates, Plato and Aristotle at the dawn of western philosophy, through the Stoics and Epicureans, to the natural law of Augustine and Aquinas, to Humean and Kantian ethics, and then to Bentham and Mill, and finally to modern day moral theorizing of myriad stripes, the core principles of non-harm, honesty, cooperativeness and beneficence remain at the heart of philosophical accounts of moral obligation. Certainly, particular theories prescribe various further obligations - but rarely do these obligations conflict with the core principles. Indeed, when an ethical theory does threaten such conflict, the theory's advocates spill much ink in 
arguing the tension to be illusory. For example, utilitarians vigorously contend that utilitarian duties do not conflict with natural justice prohibitions on harming innocents.

Turning from philosophical theorizing to moral practice (that is, from core-contentconvergence ${ }^{\mathrm{P}}$ to core content convergence itself), the basic reciprocity infusing the core principles features in the Golden Rule - prescribing that we should treat others as we ourselves would like to be treated. Many have been struck by this injunction's extraordinary prevalence - Hans Küng (1998) locates versions of it in Judaism, Islam, Jainism, Buddhism and Hinduism, as well as its canonical Christian and Confucian formulations. So too, injunctions against violence and deceit perennially feature in lists of commandments. Sissela Bok (2002) notes their presence in the Ten Commandments; in Buddhist, Jain and Confucian texts; in the Egyptian Book of the Dead; in the Icelandic Edda; and in the Bhagavad-Gita. The core principles' ubiquity is further revealed in their being argued for as basic by moral intuitionists (Kolnai 1970), those defending "common" morality (Gert 2004), those formulating general moral codes in applied ethics (Beauchamp and Childress 2009), and those developing moral minimalist codes for a global ethic (Bok 2002). All of these endeavours rely on widespread cross-cultural endorsement of the core principles.

All this furnishes reason to believe that human morality, with either or both scopequalifications noted above duly inserted, displays a substantial level of core content convergence.

\subsection{Evidence for motive plurality}

While many theorists have previously argued for (something like) core content convergence, less attention has been paid to motive plurality. In making the case for its existence in what follows, I aim to appeal only to cases where we can also find substantial core content convergence.

\section{Evidence for motive-plurality ${ }^{P}$}

Let's begin with motive-plurality ${ }^{\mathrm{P}}$ - that is, the claim that different moral philosophers propose different proximate motives. In fact, disagreement on the springs of morality pervades the history of ethics. Often the philosophical debate explicitly focuses on the proposed reasons for performing one's duties, rather than the duties' actual content. For example, in his famous Groundwork of the Metaphysic of Morals, Kant does not once impugn rival moral theories for putting forward mistaken duties. But he inveighs relentlessly against what he sees as the wrongful moral motives proposed by previous philosophers. And Kant was under no illusions about the breath-taking diversity of those motives. Castigating the "amazing medley" of empirical motives devised by philosophers "hunting everywhere for inducements to be moral," Kant (1785/2008, 4:410-411) lashed out at theories based on selfinterest, sympathy, honour, instinct, reputation, perfection, moral sensibility, and the fear of God-before putting forward his own account of reverence for law and human dignity. Thus, not only do we see philosophers putting forward moral theories developed around diverse proximate motives, we also have evidence some philosophers perceived motive-plurality ${ }^{\mathrm{P}}$ itself. Jacques Maritain nicely expressed this theme in 1947, summing up the position of the UNESCO group of philosophers informing the Universal Declaration of Human Rights 
drafting process. "Yes, we agree about the rights," he affirmed, "but on condition no one asks us why" (Glendon 2001, p. 77).

So how many different proximate motives have philosophers proposed in answer to that "why"? How can human beings come to love duty?

Let us count the ways.

With apologies for simplifying sophisticated theories into sound bites, ${ }^{6}$ a list of the philosophy's proposed proximate motives would include: psychological integrity (Plato); human excellence, completion and perfection (Aristotle, contemporary virtue theory); respect, love or fear of God (Aquinas, Augustine); personal independence and security (Stoics); empathy (Hume); projective empathy (Smith); respect for the dignity of law and law-makers (Kant, ultimately Lawrence Kohlberg); relations of care (Carol Gilligan); human sociability (Pufendorf, Grotius) and the social instincts more generally (Darwin); the internal goods created by social practices (Dewey) and of having a narrative structure to one's life (MacIntyre); mutual respect and recognition (Hegel, in some respects Levinas); authentic choice (existentialists); the distinction of internalizing special "stations" and their attendant rites (Bradley, in many respects Confucius); moral beauty (Hutcheson, Shaftesbury); making oneself capable of enriching relations with others, or with oneself (Socrates, in some respects Arendt); personal happiness and instrumental rationality (Epicurus, Hobbes, Rand, Gauthier); civic identity and solidarity (Montesquieu, in some moods Rousseau); honor and reputation (in some respects Cicero, Locke, Tocqueville; recently Appiah); respect for tradition (Burke, Roger Scruton); etiquette and courtliness (Norbert Elias); and seeing oneself as part of a collective (in some respects Émile Durkheim, Aldo Leopold) or part of a larger project (Singer).

Doubtless we could wrangle over the wording of each of these snap-classifications. ${ }^{7}$ But I daresay no-one will deny the plain fact that these proposed motives differ from one other. Motive-plurality ${ }^{\mathrm{P}}$ exists. Alongside constructing different ontologies, epistemologies and theories of mind, ethicists throughout history proposed diverse proximate motives.

\section{Evidence for motive plurality}

What can be said empirically for motive plurality itself?

\footnotetext{
${ }^{6}$ An enriched description of these proximate motives would reveal overlap between different theorists' proximate motives (e.g. similar reputational devices in Aristotle, Hume and Darwin). However, as we will see (in §3.1) with the examples of Hume and Smith, a more granular examination of each proximate motive would not necessarily increase the similarity between list-members.

${ }^{7}$ Some philosophical theories weave different motive-types together. E.g., Aristotle incorporates excellence, moral beauty, honor and psychological integrity. Such "mixed" accounts are not pluralist in my sense - they do not assert that different people each possess distinct psychological makeups driving their own moral compliance.
} 
The first point to note is that motive-plurality ${ }^{\mathrm{P}}$ can provide evidence for the wider phenomenon of motive plurality. ${ }^{8}$ This is especially so in cases where the moral theories were crafted through a searching sociological examination of the discourse, traditions, stories and practices of a given society - either the philosopher's own society (for example, Adam Smith's (1790/2006) The Theory of Moral Sentiments) or different, past societies (for example, Alasdair MacIntyre's (1981) After Virtue). In such cases, information about a particular society's actual moral practices explicitly feeds in to the development of a proposed proximate motive.

Yet even the long list of philosophers' envisaged moral springs enumerated above does not capture every reported proximate motive. There are many further, plausible proximate motives that, while they may not enjoy contemporary philosophical currency, nevertheless emerge from the different cultures' discourses and practices.

To be clear, my assertion is that all these motivational structures can be found (at least sometimes) attached to moralities overlapping on the core principles, at least with respect to treatment of the "in group". Consistent with §2.1's second scope qualification, I don't deny that many of these motives (such as tribal taboos or respect for custom) may also give rise to moralities departing from the core principles. The point is simply that people can be motivated to conscientious performance of the four core principles on the basis of the following proximate motives.

So how else may we love duty? Let us keep counting the ways.

Consider the proximate motives of: emulation of exemplars, saints and heroes; nobility and majesty; uniformity and conformity; non-theistic spirituality, mysticism and the "secular sacred"; chivalry, gallantry and gentrification; pity and compassion; principled competition, rivalry and agon; the serenity of ritual; taboo's superstitious fear; military or monastic discipline; wonder; loyalty and devotion to leaders; submission or surrender to authority; universal love and agape; veneration of custom; glory; purity and disgust; the harmony of orderliness and fittingness; courtesy and ceremony; following "nature"; gentleness; the security attending familiarity and habit; and personal-cultural investment in and ownership of specific mores.

I submit that unless we possess some powerful general reason to somehow discount all of these self-asserted explanations for moral conduct by various cultures and individuals, then they furnish us with a prima facie case for accepting the existence of a motive plurality stretching far beyond the already-long philosopher's list of moral springs.

But such a pervasive phenomenon could hardly have gone unnoticed. We saw above that some moral philosophers showed awareness of moral-motive-pluralism ${ }^{\mathrm{P}}$. Shouldn't other scholars similarly have noticed moral motive pluralism itself?

\footnotetext{
${ }^{8}$ See also n. 13 below.
} 
In fact, numerous students of human behavior have gestured towards the existence of moral motive pluralism. ${ }^{9}$ As illustrated by the opening epigrams (from Locke, Reid and Michael Walzer), many philosophers realized that different cultures possessed different values apparently driving similar moral duties. Wiggins (2005, pp. 19-20) traces back to Aristotle an ongoing tradition of thought that, "despite the manifest differences in the ways in which different peoples (and different people) are introduced to morality and participate in it, there is a common core of morality..." Fast forward to the nineteenth century, when Nietzsche's (1887/1996) Genealogy of Morals argued that people developed and engrained "good" duties for less savoury motives than those for which the same duties are now performed. Bernard Williams' (2002) more recent genealogy argued that each society has reason to construct intrinsic value for practices of truth and truthfulness - practices which are otherwise insufficiently motivated at a personal level. Anticipating the idea of moral motive pluralism, Williams (2002, p. 115) allowed that a plurality of culturally available alternatives, including honour and nobility, could be used to fill this gap in motivating the socially required virtues.

So long as an overlapping core of moral duties is acknowledged, relativist theories can also recognize moral motive pluralism. David Wong's "pluralistic relativism" recognizes a shared moral core created by what he sees as universal constraints on the evolution of moral systems. That is, moralities need to fulfil key social functions, and this creates a large area of overlap between their content. While Wong's theory centres on a plurality of moralities, rather than motives, his idea that disparate mechanisms can be responsible for the evolution of morality makes room for a diversity of (what I call) proximate motives (Wong 2009, pp. 57-59).

Moral psychologists have also tracked the phenomenon. One influential work on child development notes empirical support for the proximate motives of: social instincts; fear and guilt; reciprocal benefit; reward-reinforcement; social intelligence; awe and self-subjugation; social conformity; self-perceptions and identifications; empathy/sympathy; and parental socialization (Rest 1992, pp. 565-567, 571). Since that work, evidence has continued to mount for the causal significance of an amazing medley (to borrow Kant's expression) of psychological processes driving moral action. For example, scientists test for: the conditions under which empathy promotes helping behavior (Nichols 2004); the capacity of experiences of moral beauty to alter ethical behavior (Diessner et al. 2008), and; the significance of activities like perspective-taking to promote moral development (Gibbs 2010). The aggregate of such work suggests moral motive pluralism: if emotional contagion, beauty and perspective-taking all play a causal role in different people's moral actions, then perhaps our best theory of moral motivation should incorporate them all.

\footnotetext{
${ }^{9}$ Despite its terminological similarity, Ragnar Francén's “moral motivation pluralism” does not signify a plurality of moral motives, but rather a plurality of opinions regarding the technical question of "what it takes in terms of motivation to be a moral opinion" (2010, p. 130). Though the two notions differ, the plurality of proximate motives (my moral motive pluralism) helps explain the plurality Francén posits.
} 
Some moral psychologists have followed just this thought, and proposed theories where different proximate motives drive the moral behavior of different individuals. Lawrence Kohlberg's famous stages of moral development see learners progressing through divergent moral standpoints while accepting similar rules at each developmental stage. Full-fledged moral motive pluralism appears in modern renderings of Kohlberg's model, where a strict following of stages is relaxed, allowing different individuals to fork into different stages, and stop their development at different points (Gibbs 2010). This results in a scenario where different people obey similar duties, but (having branched into, and stopped within, different stages) possess different motivational structures. Similarly, Carol Gilligan's aptly titled In a Different Voice explicitly broached the possibility of similar morals undergirded by different emotional perspectives. ${ }^{10}$ Perhaps the closest recognition of moral motive pluralism occurs in Jonathan Haidt and Craig Joseph's (2004) work, where they argue that human moral psychology contains certain modules - self-standing intuitions attaching to factors such as harm and reciprocity - that then acquire culturally variable virtues to support them. ${ }^{11}$

One of the most influential research programs in moral psychology - stemming from the work of James Rest (1992) - supplies a different sort of evidence for moral motive pluralism. Rest's model begins by conceptually detaching moral reasoning from moral motives. He distinguishes the process (of reasoning) whereby the subject decides the morally right thing to do, from the process (of motive) where the subject weighs whether to conform to that decision. Research over recent decades confirms that these two processes differ psychologically: a subject can progress through various stages of moral reasoning without that progress determining the values the subject uses to act upon their moral judgments (Rest 1994). Psychologists thus uncover remarkably similar processes of moral reasoning from subjects across the globe-explaining the phenomena of core content convergence. But they find no such convergence on moral motive - so much so that Rest himself, after noting that none of the myriad proposed motives enjoy compelling support, eschews providing a general model for this part of his overall theory (1992, pp. 565-569). These empirical results are exactly what the hypothesis of moral motive pluralism predicts: widespread agreement on cognitive processes leading to stable moral principles - coupled with a dizzying diversity on the question of motive.

Casting our net further afield reveals additional evidence. From international relations studies come explanations of "norm emergence" where different nations adopt the same norm for quite distinct reasons, including motives of altruism, empathy, idealism, reputation, conformity and habit (Finnemore and Sikkink 1998; Risse et al. 1999). Theories of "norm localization" echo this theme, showing how different cultures locate their own traditions to ground global norms (Acharya 2004).

${ }^{10}$ Gilligan (1982). Moral motive pluralism is consistent with (but does not itself imply) Gilligan's hypothesis that different genders tend to employ different proximate motives. ${ }^{11}$ While Haidt's larger theorizing does not explicitly invoke moral motive pluralism, at times he approaches the idea. See especially, Haidt (2012, pp. 128, 368). 
Finally, one recent theory from political philosophy warrants special mention. Moral motive pluralism parallels key themes in John Rawls' (1993/2005) “political liberalism”. Rawls' groundbreaking idea considered the possibility of an "overlapping consensus" on constitutional principles of right political action emerging from a multitude of irreconcilable "comprehensive doctrines." Both moral motive pluralism and Rawls's political liberalism take as their point of departure the possibility of widespread endorsement of normative principles alongside deep disagreements on why those principles command allegiance. ${ }^{12}$ Subsequent political theory in Rawls' wake continues in the same spirit, with "political theories" of human rights positing different reasons driving different actors to acknowledge the same human rights (Beitz 2009, p. 198). Indeed, the very existence of the international human rights regime draws upon the possibility of shared agreement on norms despite widespread "moral pluralism" across the globe (Ignatieff 2001, p. 56).

For Rawls and those following in his footsteps, the puzzle here centred on metaphysical commitments: how can people who espouse different philosophical and religious beliefs endorse the same normative principles? But for those who think that people's normative commitments follow less from their abstract metaphysical beliefs, and more from their selfidentities and social relationships, then the question becomes: how can people who possess very different personalities, cultural ideals, and habits of life, endorse the same normative principles? The question, that is, implicates the puzzle of moral motive pluralism.

As this snapshot of philosophical and empirical scholarship shows, again and again scholars of human behavior approached the same truth: moral duties remain similar, but moral motives differ. Philosophers as far apart in time as Aristotle and David Wong, and as far apart in temper as John Locke and Nietzsche, displayed nascent awareness of this phenomenon. Moral psychologists provide micro-level corroboration, while international relations theories triangulate the phenomenon on a macro-scale. And the general possibility of similar norms accepted by diverse worldviews has been directly broached by contemporary scholarship on political legitimacy and human rights.

As a result, I submit we possess a strong case for acknowledging the existence of more than one-and possibly many more than one-proximate motive at work in human morality. Moral motive pluralism exists.

\section{Should moral motive pluralism impact upon our moral theorizing?}

Does the existence of moral motive pluralism matter? In this section, I argue that moral motive pluralism impacts on key evidence marshalled for specific moral theories, especially what I will term 'moral motive monist theories'. Moral motive monist theories hold up one

\footnotetext{
${ }^{12}$ Note though that political liberalism differs from moral motive pluralism insofar as it: governs only political questions and not interpersonal morality; avoids substantive claims about moral psychology; is relativized to liberal democratic cultures; and posits a "fact of pluralism" comprising a plurality of belief systems, rather than (with moral motive pluralism) a plurality of values, emotional responses, personality traits and lived practices.
} 
preferred proximate motive as the true, essential moral motive, and deny equal significance to alternative motives. Most of $\S 2.2$ 's examples of proximate motives came from moral motive monists (e.g. Kant, Hobbes, Hume).

Having considered the critical consequences of taking seriously the phenomenon of moral motive pluralism, I then turn to its potential positive contribution to moral philosophy. I suggest that a normative theory (all other things equal) should explain widespread moral phenomena. I then consider which contemporary moral theories deliver a plausible explanation of moral motive pluralism.

\subsection{Moral motive pluralism impacts on evidence marshalled by moral motive monist theories}

At first blush, we might think that moral motive pluralism cannot impact on normative moral philosophy. Moral theories provide reasons for action, after all, justified by philosophical arguments. Moral motive pluralism amounts to no more than a curious empirical phenomenon.

Upon examination, however, few philosophical arguments for moral systems proceed entirely a priori. Almost all moral theories turn out to marshal empirical and experiential evidence. While moral motive pluralism does not directly contradict the proffered evidence, the phenomenon frames such information in a larger context that weakens the information's probative value.

I have earlier argued that different philosophers develop moral theories with different proximate motives. Note a crucial corollary: since proximate motives are (at least somewhat) available to introspection, philosophers can and do employ introspectable evidence to corroborate their theory's key claims.

Consider a few quick examples of the different internal moral experiences implied by different moral theories: A Kantian agent (Kylie) will morally deliberate about whether her acts are impartial and universalizable. As she does, Kylie apprehends the moral impulsion to act as as a call of reason - an authoritative decree from her rational, thinking nature - and she feels reverence for the law and all rational law-makers (Kant 1785/2008). Contrariwise, an Aristotelian agent (Andrew) focuses on the quality of his emotional responses. Andrew ensures he faces external challenges with the proper emotion felt to the proper degree as he pursues excellence of character and a life well-lived in society (Aristotle 350BC/2002). A Humean agent's (Harry's) internal experience differs again. Picking up on how he feels about other's actions, and how they feel about his, Harry adopts a third-party perspective, prompting him to direct his sympathies in an increasingly impartial fashion (Hume 1739/1969). Surprisingly, even philosophers sharing the same tradition can develop theories expressing distinct internal lives. For instance, Adam Smith's theory of the moral sentiments follows Hume's tradition — but a Smithian agent (Sally) differs from Harry. Sally imagines herself in other's positions as she seeks out a warm buzz of human connection triggered by emotional conformity with them-even as those others seek to similarly connect to her 
(Smith 1790/2006). This process of imagination and connection leads Sally to more impartial affections and so to principled moral action.

Different moral theories thus propose different accounts of internal moral experiences, deliberations and feelings. Crucially, these different accounts allow people to test the moral theory's claims by consulting their own internal experiences.

Consider a concrete example: Picture yourself leafing through Kant's Groundwork for the first time. You find yourself nodding in agreement when Kant asserts: that his pivotal concept of the "good will" lies already present in a sound natural understanding; that the ordinary reason of mankind always holds the principle of the categorical imperative "before its eyes"; and that a feeling of reverence for the law and the dignity of rational beings accompanies moral judgment and action (Kant 1785/2008, 4:397, 401-392, 434, 454). In recognizing all these ideas, feelings and deliberations from your own inner life, you corroborate Kant's premises - you verify what Barbara Herman (1993, p. 1) calls "the intuitive basis in ordinary moral knowledge that is essential to Kant's argument." The experiences that Kant argues follow from his theory turn out to manifest within your internal life. These experiences, combined with the battery of inter-linked philosophical arguments Kant presents, provide you with strong reason to endorse Kant's moral theory as an accurate account of the moral condition. ${ }^{13}$

But awareness of moral motive pluralism calls this inference into question; it cautions you that your own internal moral life differs from the experience of others. Others - like Andrew, Sally and Harry above - might picture the "good will" differently, or not at all. They might apprehend neither reverence nor dignity in their moral life. They never witness the principle of the categorical imperative "before their eyes". Such others lack your reasons to accept Kant's arguments - and you, armed with awareness of moral motive pluralism, must share their misgivings. You find yourself wary of generalizing from your own moral experience, and from building universal moral theories from what you now see as potentially parochial introspections. Your awareness of moral motive pluralism has placed your own experiential ratification of Kant's claims in a wider context where they no longer offer his argument the same probative support. Indeed, you might worry that the fact that other people engage in conscientious moral behavior driven by rich moral experiences that don't include the Kantian experiences of good will, reverence and universalizability counts against accepting Kant's theory, given that his theory suggests all rational beings should be conscious of at least some inkling of these experiences.

I have deliberately considered Kant because he is often pictured as the "a priori" philosopher par excellence, spurning empirical and experiential evidence. But, of course, many other philosophers explicitly appeal to the evidence of internal feelings. For example, Hume (1993,

${ }^{13}$ This introspectible feature of proximate motives means that motive-plurality ${ }^{\mathrm{P}}$ provides evidence for motive plurality itself: a philosophical moral theory's popularity within a given population will be at least partially explained by the then-existing prevalence of the internal qualia associated with that theory. 
p. 277) lambasted Hobbes' egoistic account of moral dispositions, arguing that we can simply observe fellow-feelings like sympathy in action. For those whose internal lives chime with Hume's claims, Hobbes' argument falters. But for those who find themselves obeying the moral law only after reflecting upon the horror of social breakdown, it is Hume's claim, and not Hobbes', that jars with experience. Indeed, Hobbes unequivocally allowed his argument to hinge on such introspections. Leviathan begins with Hobbes (1651/2008, p. 8) arguing that a man wanting to understand the thoughts and passions of others must "looketh into himself", and consider what he himself thinks, hopes and fears. Only through so doing shall he be able to know the thoughts and passions of, "all other men, upon the like occasions." By using this key, Hobbes thinks, his reader can glean an understanding of human nature and so evaluate Hobbes' philosophy. "This kind of doctrine," he declares, "admitteth no other demonstration."

But our newfound awareness of moral motive pluralism shows how Hobbes' method can mislead. Just as it did with the arguments of Kant and Hume, moral motive pluralism cautions us against appraising moral theories on the presumption that our own internal moral life presents a standard case. ${ }^{14}$

Staying with Hobbes, moral motive monists can marshal another type of evidence for their theories. This evidence appeals to the fact that everyone displays a certain motive or emotional disposition. The monist then employs that motive to explain moral action generally. Hobbes famously does this with egoistic motives. He argues from an analysis of the passions and human experience for the ubiquity of egoistic motives (Hobbes 1651/2008, p. 84). This established, when Hobbes argues that recognizable moral behavior can follow from that motive, he seems to have provided us with a plausible (if bleak) account of moral behavior. Surely (it will be said), if a well-observed motive produces an ethic that gels with common-sense morality, this provides a powerful reason to declare that motive as the essential proximate motive. Michael Slote provides us with a recent example of the same line of argument. After first arguing for the prevalence of empathy, Slote (2007, p. 128) then stresses that empathy can explain moral judgments and distinctions at work in our ordinary moral lives.

But awareness of moral motive pluralism cautions us against such inferences. Even if everyone possesses self-interest or empathy, these dispositions may lie fallow in a person's moral life, with other commitments, self-identities and emotions shouldering the load of driving that person's moral behavior and colouring their moral experience.

In sum, when armed with awareness of moral motive pluralism, we can place these types of evidence into a larger context where they no longer offer the same support for moral motive monist theories. No longer will we be impressed when monist theories provide explanations of idiosyncratic features of our own private thoughts, or when they show how perennial

\footnotetext{
${ }^{14}$ This argument does not rely on core content convergence. Motive plurality itself suffices to make introspection about moral motives look worryingly parochial.
} 
motives can give rise to recognizable moral principles. Framed in the larger context of moral motive pluralism, such facts fail to persuade.

Of course, even without any appeal to introspected evidence, a moral theory may still persuade us on the basis of its remaining battery of philosophical arguments. While awareness of moral motive pluralism helps us appraise a moral theory's evidentiary merits, the phenomenon alone does not stand as a definitive rebuttal of any theory.

\subsection{Can existing moral theories explain moral motive pluralism?}

Consider for a moment why these normative moral theories (of Kant, Hume, Hobbes and the rest) attempt to accord with socially-observed and internally-experienced moral phenomena. Two reasons spring to mind. First, explaining these phenomena means that the philosopher is presenting a theory of morality (rather than logic, say, or aesthetics). Almost all of us possess some moral intuitions, feelings and experiences, and other's moral convictions carry potent consequences for our own lives. A theory that chimes with much of our moral experience helps us explain, understand and evaluate these important pre-existing, pre-theoretical phenomena.

Second, the existence of a fully normative moral theory, providing people with compelling reasons for action, will usually occasion at least some observable predictions. For example, such a theory will usually tell us how ordinary people apprehend morality and feel its internal force. If experience ratifies what the theory predicts on such matters, then this corroborates the theory. Contrariwise, if experience clashes with what the theory implies, then we fail to confirm one of the theory's observable predictions.

For these two reasons, we have reason to desire a moral theory that explains widespread phenomena such as moral motive pluralism. But can moral motive monist theories - or, indeed, any moral theory at all — explain moral motive pluralism? As we will see, different moral theories differentially predict the phenomenon. All else equal, we have reasons to favour theories that predict moral motive pluralism, and to resist those that don't. ${ }^{15}$

\section{The moral motive monist}

Can moral motive monist theories explain the phenomenon of moral motive pluralism? Monists can choose between two different sorts of explanations. On the first approach, monists could deny the actual existence of moral motive pluralism, arguing that ordinary people, despite their contrary assertions, in fact act on the basis of the theory's preferred moral motive (e.g., empathy). However, this preferred motive operates beneath conscious awareness, meaning people tend to misread their own motives. As a result, even though empathy (say) performs the heavy lifting in motivating everyone's consistent moral conduct, individuals mistakenly associate their moral action with other factors, perhaps ones foregrounded by their local culture. The result is the apparent (but only apparent) existence of moral motive pluralism.

\footnotetext{
${ }^{15}$ Of course, all other things are not equal. The capacity to explain observable moral phenomena constitutes just one philosophical desideratum. Endorsing a moral theory will naturally hinge on an aggregate appraisal of all the theory's strengths and weaknesses.
} 
Taking this approach carries substantial costs. It requires the moral motive monist to appeal to a host of highly controversial psychological processes - including a particularly deepseated scepticism of introspection. Plausibly, we should only discount people's self-reports of their own emotional lives when we have substantial empirical evidence to do so.

Unfortunately for this approach, the science points in the opposite direction: As previously noted, contemporary moral psychologists do not test just for the mere presence of moral feelings, but also for their casual significance in motivating action-exactly the property this approach must deny such motives possess.

The second approach allows that different proximate motives induce their holders to comply with the core principles. However, the monist sets down their preferred motive as the only genuinely justified motive, with only action taken on its basis counting as truly moral. Other impulsions amount to mere "motives" rather than "reasons." This response conceptually aligns moral motive monist theories with the existence of moral motive pluralism, but only at the cost of leaving the phenomenon unexplained.

In order to explain the phenomenon, the theorist might then gesture towards a quite separate type of empirical theory (such as the functional approach discussed below). This tack conceptually aligns a philosophical moral motive monist theory with an empirical account of moral motive pluralism. ${ }^{16}$ But it too carries costs. In the spirit of Ockham's razor, we might feel that if we are required in any case to accept the functionalist explanation of morality, then we have good reason to consider whether that functionalist theory itself provides a sufficiently plausible justification for morality - allowing the one theory to shoulder both the explanatory and the normative load. All else equal, if a reasonable philosophical moral theory can supply an elegant explanation of key features of our moral discourse and practice (like moral motive pluralism), then we have a significant reason for accepting it.

Again, these arguments do not definitively rebut moral motive monist theories. But they strip certain types of evidentiary appeal from such theories, and show that they must themselves gesture towards competing approaches to morality to explain the existence of moral motive pluralism.

\section{Functional theories}

If moral motive monist theories fail to explain the phenomenon, can others do better? Consider "functional" theories of morality, which assert that morality performs a specific social function. With an eye to explaining moral motive pluralism, we can add to these theories the idea that this universal function can be filled in different ways - a possibility we already saw (in §2.2) mooted in the work of Williams and Wong.

\footnotetext{
${ }^{16}$ While I will not pursue the case here, it is at least arguable that Kant provides an example of this position. In his more technical and philosophical works he puts forward a moral philosophic justification for the Categorical Imperative (justifying a specific proximate motive implicating reason and dignity). Yet in his more empirical works Kant puts forward a social theory of morality that provides an alternative explanation (but not justification) of existing moralities, and — at least potentially — their diverse proximate motives.
} 
For example, suppose with Wong (2009, p. 46) that the social function of morality is to "promote social cooperation". It could be argued that, taking what we know of human beings, any moral theory capable of fulfilling this function must contain the core principles. By prohibiting harmful and intrusive acts, demanding people interact honestly, ensuring a minimum level of cooperativeness to facilitate society's functioning, and making sure vulnerable people receive help (so necessity does not drive them to harm and steal), such a morality eliminates the main triggers of social conflict. The functional theory of morality requires that all people obey these core principles necessary for social peace - but the theory can be eclectic about what actually compels any given person to comply with those principles. Different individuals and societies might develop different social resources to ensure compliance. The result would be moral motive pluralism: convergence on the core principles (provided by morality's ubiquitous function) combined with a plurality of proximate motives (provided by the different traditions, practices and discourses socially constructed to fulfil the function). This functional explanation elegantly accounts for the striking psychological diversity of proximate motives highlighted earlier. ${ }^{17}$ In order to motivate intrinsic respect for the four principles, societies and individuals are pressured to use whatever psychological resources they happen to possess, or are capable of cultivating. The function must be fulfilled, and any tool capable of being bent to the task can be employed.

Still, there is a complication here. The functional theory needs to tell us why the proximate motives were created at all. The theory needs to explain why the function itself wasn't enough to motivate individuals and communities. Now if the proximate motives were only supplementary supports for performing the functionally necessary acts, this would present few problems. Humans often develop ancillary motives for performing otherwise necessary acts. However, proximate motives do not merely offer support - rather, they colonize their holder's ethical life. The function itself recedes from view, with the result that we are left with no consensus on the function of morality, or even that morality has a function. Yet, as Nietzsche (1887/1996) once queried of such views, if every society requires its morality to perform this vital function - requires it so strongly that it develops proximate motives to impel the performance of moral duties - then how could the society ever come to forget the function's existence?

One response to this line of thought might be to query whether the function really disappears completely from view. Whatever our other views on morality may be, perhaps enough people think morality should encourage peace, coordination and social flourishing. Acts in line with these goals are thus perceived as collectively desirable. Even when other social resources are developed to motivate individual compliance, these over-arching functions are well-known enough to keep interpersonal moral duties orbiting close to the four core principles necessary for social coordination.

A second response could give the functionalist theory a rights-based inflection.

Contemporary human rights aim to protect a prized set of personal freedoms, interests and

${ }^{17}$ See especially the text to nn.2-3 above. 
capabilities - the 'permanent interests of man', as Mill once expressed the idea. ${ }^{18}$ It seems plausible to suppose that — all other things equal — human individuals and groups work to protect and promote these interests wherever possible. The Universal Declaration of Human Rights itself implies such a tendency; in a Lockean spirit, the Declaration's Preamble suggests that if human rights are left unprotected, citizens will be compelled to take recourse in rebellion in order to protect them. Theorists like Shue (1980, pp. 13, 32-34) and Buchanan (2010, pp. 54-55) develop this line of thought by seeing human rights as responses to 'standard threats' to the protected interests. If we can safely assume that rape, theft, fraud, murder, exploitative free-riding and desperate material straits count as standard threats to these key human interests, then we have a consistent social (and sometimes physical) pressure demanding moral norms deal seriously with these threats. On this footing, the ongoing force for the core principles radiates outwards from individuals' and groups' perennial desires to protect their key interests, continuously massaging the existing moral norms towards requiring honesty, non-violence, coordination and beneficence. In this case, the overall 'function' may recede from view, but specific individuals and groups rally their forces whenever they perceive that the reigning moral code fails to protect them from these standard threats.

A final response, following Wong's line of thought, could propose that societies never knew the function in the first place. Rather, natural or cultural selection simply weeded out moral codes incapable of ensuring social stability, resulting in major substantive similarities across codes without any conscious awareness by the society-members themselves. In a process of group selection (see Haidt 2012), societies with moralities capable of encouraging constructive and productive social interactions flourished. Contrariwise, societies with moralities incapable of minimizing social conflict imploded or were out-competed by their neighbors.

Summing up, accepting the reality of the phenomenon of moral motive pluralism does not definitively mandate accepting functional theories, nor does it rule out moral motive monist theories. Nevertheless, moral motive pluralism calls into question some of the key (introspected) evidence drawn upon by moral motive monist theories, and offers positive reason to accept functional theories like Wong's and Williams's.

\section{Conclusion}

I have argued that when it comes to motivating morality, there are many ways to resist skinning a cat. Even if we qualify the ambit of moral motive pluralism, applying it only to members of post-Enlightenment Western societies' treatment of their fellows, the phenomenon holds clear philosophic importance. The more we uncover evidence of it pervading cultures and history, the more the phenomenon cries out for explanation.

\footnotetext{
${ }^{18}$ Mill (1859/2003, p. 10). Mill himself clearly understood the enticing array of moral motives that could be called upon to impel duties protecting these interests (1861/2001, p. 29).
} 
Moral motive pluralism matters. Its existence threatens some widely-employed arguments for moral theories, especially moral motive monist theories. All else equal, we have reason to endorse moral theories that explain such widespread moral phenomena. I argued that moral theories focussing on a particular function for morality, rather than a particular proximate motive, might be well-placed to furnish the desired explanation.

In closing, I would like to draw on the 'rights-based' approach advanced in the previous section to hint that a moral theory vindicating moral motive pluralism might answer the observable ways human beings resemble each other-and the ways they differ. Human similarities, we might think, set the content of morality's duties. Whatever else we may desire, we all need protection from harm and coercion. So too, we all need some of the basic advantages afforded by human society, so we require honesty, cooperativeness and mutual support. But when it comes to what we all find most valuable in our lives, what emotionally grips us and drives us, individuals and cultures could hardly be more diverse. If we must weld morality into our characters with a force capable of constraining our primeval drives, then it must tap into our deepest values and emotions. But there is no one answer to what our deepest values and emotions are. And that means that Amy, say, needs to have a proximate motive tailored to her, Amy, and it will differ from what motivated Aristotle, or Hume, or Kant - or what motivates you or me. In this way, a moral theory vindicating moral motive pluralism might respond at once to the similarity of people's fundamental needs, and the diversity of their emotional lives.

Acknowledgements This article was many years in the making, and it is impossible here to acknowledge all those whose helpful contributions spurred its development. But particular thanks go to the philosophy cohort at The University of Queensland, and to Michael Vincent, Dave Kinkead, Paul Formosa and (especially) Rachael Briggs, whose penetrating criticisms honed much of the argument presented in Section 3.

\section{References}

Acharya, A. (2004). How Ideas Spread: Whose Norms Matter? Norm Localization and Institutional Change in Asian Regionalism. International Organization, 58(2), 239275.

Aristotle (350BC/2002). Nicomachean ethics (J. Sachs, Trans.). Newbury, MA: Focus Publishing/R. Pullins.

Beauchamp, T. L., \& Childress, J. (2009). Principles of biomedical ethics (6th ed.). New York: Oxford University Press.

Beitz, C. (2009). The Idea of Human Rights. New York: Oxford University Press.

Bok, S. (2002). Common Values. London: University of Missouri Press.

Brink, D. O. (1984). Moral Realism and the Sceptical Arguments from Disagreement and Queerness. Australasian Journal of Philosophy, 62, 111-125.

Buchanan, A. (2010). Human Rights, Legitimacy and the Use of Force. New York: Oxford. 
Diessner, R., Solom, R. C., Frost, N. K., Parsons, L., \& Davidson, J. (2008). Engagement With Beauty: Appreciating Natural, Artistic, and Moral Beauty. The Journal of Psychology, 142(3), 303-329.

Finnemore, M., \& Sikkink, K. (1998). International Norm Dynamics and Political Change. International Organisation, 52(4), 887-917.

Francén, R. (2010). Moral Motivation Pluralism. Journal of Ethics, 14, 117-148.

Gert, B. (2004). Common Morality: Deciding What to Do. New York: Oxford University Press.

Gibbs, J. (2010). Moral Development and Reality: Beyond the theories of Kohlberg and Hoffman (2nd ed.). Boston: Penguin Academics.

Gilligan, C. (1982). In a different voice: Psychological theory and women's development. Cambridge, Mass.: Harvard University Press.

Glendon, M. A. (2001). A world made new: Eleanor Roosevelt and the Universal Declaration of Human Rights. New York: Random House.

Haakonssen, K. (1996). Natural law and moral philosophy: from Grotius to the Scottish Enlightenment. New York: Cambridge University Press.

Haidt, J. (2012). The Righteous Mind: Why Good People are Divided by Politics and Religion. London: Penguin.

Haidt, J., \& Joseph, C. (2004). How Innately Prepared Intuitions Generate Culturally Variable Virtues. Daedalus, 133(4), 55-66.

Herman, B. (1993). On the value of acting from the motive of duty. In The practice of moral judgment (pp. 1-22). London: Harvard University Press.

Hobbes, T. (1651/2008). Leviathan. New York: Oxford University Press.

Hume, D. (1739/1969). A Treatise of Human Nature. Baltimore, Md.: Penguin Books.

Hume, D. (1993). An Enquiry Concerning Human Understanding. Cambridge: Hackett.

Ignatieff, M. (2001). Human Rights as Politics and Idolatry. Princeton: Princeton University Press.

Kant, I. (1785/2008). The moral law: Groundwork of the Metaphysic of Morals (H. Paton, Trans.). New York: Hutchinson's University Library.

Kolnai, A. (1970). Moral Consensus. Proceedings of the Aristotelian Society, 70, 93-118.

Küng, H. (1998). A global ethic for global politics and economics. New York: Oxford University Press.

Locke, J. (1690). An Essay Concerning Human Understanding (2nd ed.). London: Thomas Basset.

MacIntyre, A. (1981). After virtue: a study in moral theory. London: Duckworth.

Mill, J. S. (1859/2003). On Liberty. Cambridge: Hackett.

Mill, J. S. (1861/2001). Utilitarianism (2nd ed.). Cambridge: Hackett.

Nichols, S. (2004). Sentimental rules: on the natural foundations of moral judgment. New York: Oxford University Press.

Nietzsche, F. (1887/1996). On the Genealogy of Morals (D. Smith, Trans.). New York: Oxford University Press.

Rawls, J. (1993/2005). Political Liberalism (Expanded ed.). New York: Columbia University Press. 
Rest, J. (1992). Morality. In P. Mussen (Ed.), Handbook of Child Psychology (4th ed., Vol. III, pp. 556-629). New York: John Wiley \& Sons.

Rest, J. (1994). Background: Theory and Research. In J. Rest, \& D. Narvez (Eds.), Moral Development in the Professions: Taylor \& Francis.

Risse, T., Ropp, S. C., \& Sikkink, K. (Eds.). (1999). The Power of Human Rights:

International norms and domestic change. New York: Cambridge University Press.

Rokeach, M. (1976). Beliefs, Attitudes and Values: A Theory of Organization and Change. London: Jossey-Bass Publishers.

Shue, H. (1980). Basic Rights: Subsistence, Affluence and US Foreign Policy. Princeton: Princeton University Press.

Slote, M. (2007). The Ethics of Care and Empathy. New York: Routledge.

Smith, A. (1790/2006). The Theory of Moral Sentiments (6th ed.). Mineola, New York: Dover Publications.

Walzer, M. (2000). Just and unjust wars (3rd ed.). New York: Basic Books.

Wiggins, D. (2005). Objectivity in Ethics. Ratio, 18, 1-26.

Williams, B. (2002). Truth \& truthfulness: an essay in genealogy. Princeton, N.J.: Princeton University Press.

Wong, D. B. (2009). Natural Moralities: A Defense of Pluralistic Relativism. New York: Oxford University Press. 